gonococcal arthritis-experience in Durban, South Africa. Br J Rheumatol 1994; 33: 840-1.

5. Kambal AM. Arthritis due to a penicillinase-producing Neisseria gonorrhoeae from Saudi Arabia. Infection 1995; 23: 121-3.

6. Cucurull E, Espinoza LR. Gonococcal arthritis. Rheum Dis Clin North Am 1998; 24: 305-22.

7. van Duynhoven YT. The epidemiology of Neisseria gonorrhoeae in Europe. Microbes Infect 1999; 1: 455-64.

8. Enfermedades de Transmisión Sexual. Dossier informativo de Infomundi, Servicio de Información y Documentación sobre el Tercer Mundo creado por la ONG Medicus Mundi en 1996. Febrero 1997.

9. Aguado Acín MP, Richi Alberti P. Artritis agudas, diagnóstico y tratamiento. Jano 1997; 53: 1222-49.

10. Manual Merck. Enfermedades de transmisión sexual. (164). 2000 Merck Sharp \& Dohme de España, S. A.

\section{Nuevos marcadores en el manejo del nódulo tiroideo}

\section{Sr. Director:}

La probabilidad de que un nódulo tiroideo gammagráficamente frío sea maligno es del 5-25\%. La punción-aspiración con aguja fina (PAAF) es generalmente aceptada como la técnica de elección para su estudio, sin embargo su interpretación (aun siendo clave para la decisión de un eventual tratamiento quirúrgico) tiene importantes limitaciones. Es por esto que desde hace algunos años se vienen estudiando diferentes marcadores moleculares que nos puedan ayudar en los casos dudosos (TPO47, galectina3, CD44v6, c-Met, CK-19, etc.). De entre ellos los más estudiados son TPO47 y galectina-3.

TPO47 es un anticuerpo IgG monoclonal de ratón capaz de reconocer un epitopo lineal de 9 aminoácidos (residuos 713-721) de la tiroperoxidasa (TPO) humana $(1,2)$. La conservación de la normal expresión de TPO en el tirocito supone un importante dato de benignidad. Se ha demostrado la utilidad de este anticuerpo en la clínica para diferenciar folículos tiroideos benignos (tinción en $80 \%$ de células) de los malignos ( $<80 \%$ de células positivas, generalmente <20\%). En el estudio prospectivo más importante realizado hasta la fecha (124 muestras) utilizando TPO47 en aspirados de nódulos sólidos tiroideos se comprobó su excelente sensibilidad y especificidad $(1,00$ y 0,99 , respectivamente).

Por su parte, galectina-3 es una molécula relacionada fundamentalmente con la adhesión celular. Su sobreexpresión en el tirocito supone un dato de malignidad. Su utilidad clinica también está demostrada y en el estudio prospectivo más amplio realizado hasta la fecha en muestras de PAAF y analizando galectina-3 (1.009 pacientes) se describen unas cifras de sensibilidad y especificidad también incontestables $(0,99$ y 0,98 , respectivamente) (4).

Nuestro grupo ha estandarizado recientemente (5-8) la técnica de inmunocitoquímica para TPO47 para aplicar en muestras de PAAF, y logrado estudiar prospectivamente 31 pacientes entre los cuales tenemos 2 casos diagnosticados citológicamente como malignos/sospechosos ("adenoma folicular sospechoso" y "proliferación folicular de células de Hurthle") en los que pudimos demostrar su benignidad previamente a la intervención, lo que correspondió con el diagnóstico anátomo-patológico final de las muestras operatorias.

Queremos hacer hincapié en que, en comparación con la citología convencional, la diferencia positivo/negativo para TPO47 y galectina-3 es tan evidente que, a la luz de lo publicado y nuestra propia experiencia, consideramos que el actual esquema del manejo del nódulo tiroideo ya no puede sustentarse sólo en las características morfológicas clásicas, sino que debemos empezar a aplicar, al menos en los casos más dudosos, los conocimIentos y técnicas moleculares a las muestras de PAF (p.e.: inmunocitoquímica para TPO47 y galectina-3). Este análisis adicional supone aumentar notablemente la exactitud diagnóstica de la PAAF y evitar un número importante de tiroidectomías innecesarias con lo que ello supone de coste personal, social y económico asociados.

\section{T. Jiménez, A. Rodríguez, P. Vidal-Ríos ${ }^{1}$}

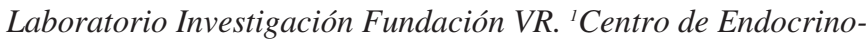
logía. Hospital de Día de Diabetes. La Coruña

1. De Micco C, et al. Inmunohistochemical study of thyroid peroxidase in thyroid neoplastic disorders. Ann Endocrinol 1988; 3: 194.

2. De Micco $\mathrm{C}$, et al. In situ hybridization and inmunochemistry study of tyroid peroxidase expression in thyroid tumor. Thyroid 2000; 10, 2: 109115.

3. Christensen L, Blichert-Toft M, Brandt M, et al. Thyroperoxidase (TPO) immunostaining of the solitary cold thyroid nodule. Clin Endocrinol 2000; 53: 161-169.

4. Bartolazzi A, Gasbarri A, Papotti M, et al. Application of an immunodiagnostic method for improving preoperative diagnosis of nodular thyroid lesions. Lancet 2001; 357: 1644-1650.

5. Rodríguez A, Jiménez T, Hofmann LH, Matías X, Vidal-Ríos P. Inmunocitoquímica con mAbTPO47 en muestras de PAAF de nódulos tiroideos: aportación metodológica [abstract] Libro XIV Congr. Soc Gal Endocr Nutric, 2001 p. 8

6. Vidal-Ríos P, Rodríguez A, Hofmann L, Matías X, Jiménez T. Primeras impresiones sobre la utilidad de la TPO47 en PAA de nódulos tiroideos [abstract]. Barcelona: Endocrinol Nutric 2002 (Supl. 1): 98, 8.

7. Rodríguez A, Jiménez T, Vidal-Ríos P. Marcadores moleculares para la valoración clínica del nódulo tiroideo. Endocrinal Nutric 2003; 50: 6675 .

8. Vidal-Ríos P, Rodríguez A, Bravo S, et al. A panel of three molecular markers for the clinical assesment of thyroid nodules using fine needle aspiration (abstract) Lyon Eur Congr. Endocrinal PO937, 2003.

\section{Hipotiroidismo, anemia hemolítica y}

crioglobulinemia en una paciente con hepatitis por virus C: eficacia del tratamiento con interferón alfa

\section{Sr. Director:}

La infección crónica por virus de la hepatitis C (VHC) se asocia a un amplio abanico de manifestaciones autoinmunes, entre las que cabe destacar la crioglobulinemia, la glomerulonefritis membrano- proliferativa, el síndrome de Sjögren, la anemia hemolítica o la tiroiditis autoinmune. A veces las herramientas terapéuticas disponibles ven limitada su eficacia al provocar efectos secundarios similares a las manifestaciones que pretendemos controlar, como la anemia hemolítica por interferón o ribavirina, o la tiroiditis por interferón. No obstante, si es la replicación viral exagerada la desencadenante de la respuesta inmune, sólo mediante su reducción lograremos el control del proceso. El caso que presentamos a continuación ilustra esta aseveración.

Se trata de una paciente de 71 años de edad con antecedentes de cardiopatía hipertensiva, que ingresa por cuadro de pérdida de peso de unos $4 \mathrm{~kg}$ en los últimos meses, astenia, anorexia y postración, así como diarreas intermitentes, pastosas, en número de 3-4 al día. Unos seis meses antes del ingreso había comenzado con parestesias en miembros inferiores por lo que se le realizó un estudio electrofisiológico que reveló un patrón de polineuropatía 
mixta sensitivo-motora. Unos 5 meses antes del ingreso había presentado una trombosis incompleta de la vena central de la retina en ojo derecho. La paciente había sido sometida también a colonoscopia y biopsia de colon (cuyo resultado fue el de mucosa normal). Existía el antecedente de un bocio multinodular hipofuncionante, con nódulo frío acompañante, sometido a estudio citológico (sin signos de malignidad), en tratamiento con $75 \mu \mathrm{g}$ de tiroxina diarios. En una analítica previa al ingreso se había evidenciado una anemia con hemoglobina de 7,1 g/dl y hematocrito de 20,6\% ; unas plaquetas de $585.000 / \mathrm{mm}^{3}$, un deterioro de la función renal con una creatinina de $2,3 \mathrm{mg} / \mathrm{dl}$ y una serología positiva frente al virus $\mathrm{C}$ de la hepatitis. Refería la aparición de lesiones sugestivas de livedo reticularis en los últimos meses y episodios de cianosis y dolor en pulpejos de los dedos de ambas manos, especialmente con el tiempo frío.

La exploración física al ingreso muestra palidez marcada, lesiones purpúricas en miembros inferiores y cianosis en ambas manos, con pulsos radiales presentes. La analítica al ingreso muestra anemia importante con hemoglobina de 5,6 g/dl, LDH de $637 \mathrm{U} / \mathrm{l}$, sideremia de $272 \mathrm{mg} / \mathrm{dl}$, ferritina de $1.914 \mathrm{ng} / \mathrm{ml}$, transferrina de $233 \mathrm{mg} / \mathrm{dl}$, índice de saturación de 82,7\%. Coombs directo negativo. Reticulocitos $69,5 \times 10^{9} / 1$, con un $31 \%$ de reticulocitos inmaduros. Se confirma la existencia de serología positiva frente al virus $\mathrm{C}$ de la hepatitis, genotipo IB, con carga viral $633.000 / \mathrm{ml}$. Ante la clínica sugestiva de crioglobulinemia se determina complemento $\left(\mathrm{C}_{3}=42\right.$ y $\left.\mathrm{C}_{4}=2 \mathrm{mg} / \mathrm{dl}\right)$; crioglobulinas, que son positivas -aunque no se disuelven en su totalidad a $37^{\circ} \mathrm{C}$; factor reumatoide, negativo; e inmunoglobulinas, normales. En el crioprecipitado de observa una banda monoclonal. Anticuerpos antifosfolípido negativos.

Se instaura inicialmente tratamiento con corticoides, no lográndose mejoría alguna. Por ello se instaura posteriormente tratamiento con interferón alfa 3 millones de unidades tres veces por semana y ribavirina $1.000 \mathrm{mg} /$ día, persistiendo la anemia, que requiere transfusiones frecuentes para mantener niveles de hemoglobina superiores a $8 \mathrm{~g} / \mathrm{dl}$. Se decide entonces suspender ribavirina y dejar únicamente tratamiento con interferón, con lo que se logra mejoría de la función renal (creatinina $1,1 \mathrm{mg} / \mathrm{dl}$ ), mejoría progresiva de la diarrea hasta su prácticamente total desaparición, de las lesiones cutáneas, de la cianosis distal y de la anemia, no habiendo necesitado en los tres últimos meses nuevas transfusiones, oscilando la hemoglobina entre $9,1 \mathrm{mg} / \mathrm{dl}$ y $10,2 \mathrm{mg} / \mathrm{dl}$.

Durante los seis meses que lleva actualmente en tratamiento con interferón la función tiroidea ha permanecido normal $\left(\mathrm{T}_{4}\right.$ libre de $\left.1,56 \mathrm{ng} / \mathrm{dl}\right)$ sin haber variado la dosis de tiroxina $(75 \mu \mathrm{g} / \mathrm{día})$.

Desde hace varios años se conoce la relación del virus de la hepatitis C con la crioglobulinemia (1), así como con otras manifestaciones sistémicas incluyendo hipotiroidismo, con o sin autoanticuerpos antitiroideos circulantes (2). El caso que presentamos reúne hechos clínicos típicos de crioglobulinemia, hipocomplementemia y criglobulinas positivas en sangre, por lo que el diagnóstico parece incuestionable. La relación causal con el hipotiroidismo es menos clara, ya que puede ser coincidente sólo. El cuadro diarreico estudiado repetidamente mediante enema opaco, colonoscopia e incluso biopsia, no guarda relación con la afectación tiroidea y ha mejorado tras el tratamiento con interferón. Aunque especulativo, es posible que dicho cuadro obedezca a una colitis colágena y/o vasculitis visceral secundaria a la crioglobulinemia, como se ha descrito en esta entidad (3).

Clásicamente el tratamiento de la crioglobulinemia se realiza con corticoides e inmunosupresores. Cuando la causa es una hepatitis $\mathrm{C}$ o $\mathrm{B}$ este tratamiento se asocia a un incremento del riesgo de estimulación de la replicación viral,por lo que la teórica mejoría derivada de frenar el fenómeno vasculítico mediante inmunosupresión se ve contrarrestada por el continuo aporte de nuevos antígenos virales. Por eso se ha ensayado el tratamiento antiviral con interferón y ribavirina, en general con buenos resultados (4). No obstante no debemos olvidar que la ribavirina puede provocar anemia hemolítica, fenómeno que también se puede observar en pacientes afectos con VHC con o sin crioglobulinemia (5). La respuesta de la anemia hemolítica de nuestra paciente al tratamiento con ribavirina fue pobre por lo que decidimos suspenderla. Por otro lado, se ha incriminado también al interferón en el desarrollo no sólo de anemia hemolítica sino de tiroiditis autoinmune (6), entre otros efectos secundarios, a veces tan graves que obligan a la interrupción terapéutica $(7,8)$. A su vez se discute si realmente la hepatitis $\mathrm{C}$ provoca hipotiroidismo o tiroiditis autoinmune, aunque la prevalencia de ambas situaciones está incrementada en pacientes con hepatitis C (9). Lo cierto es que aquellos pacientes que presentan anticuerpos antitiroideos y son tratados con interferón alfa desarrollan con mucha frecuencia enfermedad tiroidea clínicamente evidente. Otros desarrollan hipotiroidismo o agravan un hipotiroidismo preexistente $(9,10)$. Sin embargo, en nuestro caso no ha habido modificación de la función tiroidea ni de los anticuerpos antitiroideos con el tratamiento con interferón. En cambio sí hemos asistido a una marcada mejoría clínica de la paciente. Nuestro caso ilustra por lo tanto que las manifestaciones de la crioglobulinemia relacionada con el VHC mejoran claramente con interferón y que la presencia de anemia hemolítica o hipotiroidismo asociados no deben suponer una contraindicación para dicho tratamiento.

\section{A. Castellano Higuera, E. González Reimers, B. Alarcó Her- nández ${ }^{1}$, F. Santolaria Fernández, M. Rodríguez Gaspar}

\section{Servicios de Medicina Interna y ${ }^{\prime}$ Laboratorio. Hospital Universi-} tario. Tenerife

1. Agnello V, Chung RT, Kaplan LM. A role for hepatitis C virus in type II cryoglobulinemia. N.Engl J Med 1992; 327: 1490-5.

2. Gumber SC, Chopra S. Hepatitis C: a multifaceted desease. Review of extrahepatic manifestations. Ann Intern Med 1995; 123: 615-20.

3. Jones MP, Pandak WM, Moxley GF. Chronic diarrhea in essential mixed cryoglobulinemia: a manifesation of visceral vasculitis? Am J Gastroenterol, 1991; 86: 522-4.

4. Lamprecht P, Moosig F, Gause A, Herlyn K, Csernok E, Hansen H, et al. Immunological and clinical follow up of hepatitis $\mathrm{C}$ virus associated cryoglobulinaemic vasculitis. Ann Rheum Dis 2001; 60: 385-90.

5. Chao TC, Chen CY, Yang YH, Chen PM, Chang FY, Lee SD. Chronic hepatitis $\mathrm{C}$ virus infection associated with primary warm-type autoimmune haemolytic anaemia. J Clin Gastroenterol 2001; 33: 232-3.

6. Carella C, Mazziotti G, Morisco F, Manganella G, Rotondi M, Tuccillo $\mathrm{C}$, et al. Long term outcome of interferon-a induced thyroid autoimmunity and prognostic influence of thyroid autoantibody pattern at the end of treatment. J Clin Endocrinol Metab 2001; 86: 1925-30.

7. Koff RS. Interferon a for chronic hepatitis $C:$ Reducing the uncertainities. Ann Intern Med 1997; 127: 918-20.

8. García Gracia B, Sancho Bueso T, Gil Catalinas F, Bernardino de la Serna JI, García Puig J. Isquemia de miembros inferiores en pacientes con hepatitis por virus de la hepatitis $\mathrm{C}$ tratados con interferón alfa. Rev Clin Esp, 2001; 201: 283-4.

9. Deutsch M, Dourakis S, Manesis EK, Gioustozis A, Hess G, Horsch A, Hadziyannis S. Thyroid abnormalities in chronic viral hepatitis and their relationship to interferon alfa therapy. Hepatology 1997; 26: 20610.

10. Watanabe U, Hasimoto E, Hisamitsu T, Obata H, Hayashi N. The risk factor for development of thyroid disease during interferon-a therapy for chronic hepatitis C. Am J. Gastroenterol 1994; 89: 399-403. 